\title{
Teaching students to teach patients: A theory-guided approach
}

\author{
Lori Candela*1, Linda B. Piacentine ${ }^{2}$, Kathleen L. Bobay ${ }^{3}$, Marianne E. Weiss ${ }^{2}$ \\ ${ }^{1}$ School of Nursing, University of Nevada, Las Vegas, United States \\ ${ }^{2}$ College of Nursing, Marquette University, Milwaukee, United States \\ ${ }^{3}$ Marcella Niehoff School of Nursing, Loyola University, Chicago, United States
}

Received: April 5, 2018

DOI: $10.5430 /$ jnep.v8n11p92
Accepted: June 27, 2018

Online Published: July 8, 2018

URL: https://doi.org/10.5430/jnep.v8n11p92

\begin{abstract}
Nurses in every setting provide patient teaching on a routine basis, often several times a day. Patient teaching skills are essential competencies to be developed during pre-licensure nursing education. While students learn what to teach for specific conditions, they often lack competence in how to teach in ways that individualize and optimize patient learning. The ultimate goal of patient teaching is to arm patients with the knowledge and skills, and the desire and confidence in their ability to reach their targeted health outcomes. We describe the creation of a theoretical framework to guide development of patient teaching skills. The framework, rooted in the contemporary health care values of patient-centered care, is a synthesis of four evidence-based approaches to patient teaching: patient engagement, motivational interviewing, adult learning theory, and teach-back method. Specific patient teaching skills, derived from each of the approaches, are applied within the context of discharge teaching, an important nursing practice linked to patient outcomes. This exemplar emphasizes the use of critical teaching process skills and targeted informational content. An online student learning module based on the theoretical framework and combined with simulation experiences provides the nurse educator with one strategy for use with nursing students. The theoretical framework has applicability for skill development during pre-licensure education and skill refinement for nurses in clinical practice.
\end{abstract}

Key Words: Patient teaching, Discharge teaching, Patient engagement, Motivational interviewing, Adult learning theory, Teach-back method

\section{INTRODUCTION}

While theories and models abound regarding teaching, learning, and learners that have many overlapping ideas, ${ }^{[1]}$ a need remains to identify core concepts that are directly actionable for nurses learning the interactive art of patient teaching. As key health care professionals, nurses need to align their practice with national health care initiatives to achieve necessary improvements in patient health care experiences and outcomes. ${ }^{[2]}$ Nurses must change practice behaviors away from teaching as information-giving toward a dynamic partnership of information sharing and shared decision making with the patient. ${ }^{[3]}$ This conceptual change will lead to demonstrable results of improved patient health behaviors. The purpose of this article is to share a newly synthesized framework to guide student learning of patient teaching. The exemplar of discharge teaching, a nursing process aligned with national goals to improve patient experience of care and health outcomes, is used to demonstrate how the framework can be applied to teach nursing students about how to improve patient teaching.

*Correspondence: Lori Candela; Email: lori.candela@unlv.edu; Address: School of Nursing, University of Nevada, Las Vegas, United States. 
The genesis of our theoretical framework emerged from our previous research in clinical practice settings on hospital nurse contribution to readmission reduction through discharge preparation. ${ }^{[4-7]}$ What we learned from this research was that the quality of discharge teaching impacted readiness for discharge and, ultimately, post-discharge coping difficulty and readmission. Specifically, we found that how nurses teach impacts these outcomes $;^{[6]}$ in the presence of poor quality teaching, content delivered is not necessarily content well received. In developing a measure of discharge teaching for these studies, we reviewed literature on discharge teaching and general patient teaching sources. ${ }^{[7-12]}$ What emerged from this review were four evidence-based approaches to discharge teaching (patient engagement, adult learning theory, motivational interviewing, and the teachback method) and 13 teaching skills aligned with these approaches. Through triangulation methods, ${ }^{[12]}$ a synthesized model, the Theoretical Framework to Guide Patient/Family Teaching emerged. It became apparent that this framework was broadly applicable to many patient teaching situations, not solely discharge teaching.

\section{BACKGROUND}

In every encounter with patients, nurses teach through information sharing, clarification, reinforcement, demonstration, and role-modeling. ${ }^{1]}$ Pre-licensure nursing education includes content on patient teaching, with the focus on use of adult learning principles for teaching content relevant to the patient's health condition. In clinical practica, students are exposed to electronic flowsheets which require documentation of patient teaching based on disease-specific clinical guidelines, for example, guidelines for heart failure teaching. ${ }^{[13]}$

Discharge teaching is a primary function of hospital-based nurses. ${ }^{[14]}$ While preparatory teaching for discharge should be incorporated into every patient encounter throughout the patient's hospital stay, ${ }^{[15,16]}$ it becomes a focal priority near the time of discharge. This teaching is intended to prepare the patient and family/caregiver for the transition from hospital to home. ${ }^{[14]}$ Traditional nursing approaches to discharge teaching often involve unidirectional communication such as telling the patient what to do after discharge and providing those instructions in standardized written form. Sometimes, an instructional video or return skill demonstration is used. This may be expedient for nurses but not effective for those being discharged, as indicated by readmitted patients who report confusion or even no memory of discharge teaching. ${ }^{[17]}$ Patients also report that discharge instructions often are not understood because the language used by providers is confusing or unfamiliar. ${ }^{[18]}$ Part of the issue with lack of patient

Published by Sciedu Press understanding of discharge education is that nurses are not comfortable or proficient in all areas of patient teaching. ${ }^{[19]}$ Additionally, nurses report lack of knowledge regarding how people learn, lack of time, and lack of undisturbed settings as barriers to patient teaching. ${ }^{[20]}$ Nursing education can make a real impact in how graduates have been pedagogically developed to teach patients in every setting.

Improving hospital discharge process and outcomes has been a national priority in the effort to reform health care. ${ }^{[8,21]}$ Discharge teaching serves as an exemplar of the need for refocusing patient teaching from education for knowledge transfer to education targeted to engage patients in learning to manage their care at home. Standardized educational content, as part of disease-specific management programs, has had some positive impact on knowledge retention, self-care at home, medication adherence, and readmissions. ${ }^{[9,22-24]}$ However, recent research has consistently demonstrated that, although discharge teaching content is important, it is the teaching skills of discharging nurses that is a critical factor in patient readiness for hospital discharge, difficulties with post-discharge coping, and return to the hospital for readmission or an emergency department visit. ${ }^{[4,6,7]}$ Good content in the presence of poor teaching does not achieve these key outcomes of discharge teaching. Recommendations for improving discharge teaching emphasize a patient-centered approach in which both the content and method of teaching are individualized to the patient's characteristics and situation, rather than the typical approach of standardized information based on the patients' diagnosis. ${ }^{[8]}$

Improving nurses' proficiency in patient teaching is a proactive approach to addressing patient concerns with the instructions they receive. Developing high quality patient teaching skills is essential for preventing adverse outcomes associated with poor information exchange between providers and patients. As a foundational component of patient care, skill building in patient teaching, including content knowledge and teaching process, should be a core competence developed within prelicensure curricula. This education should embrace contemporary evidence-based approaches to teaching and learning.

\section{THEORETICAL FRAMEWORK TO GUIDE PATIENT/FAMILY TEACHING}

The purpose of this theoretical framework is to provide guidance to pre-licensure and practicing nurses in developing and refining patient teaching skills. The framework advocates for a patient-centered approach to patient teaching integrating four evidence-based approaches: Patient engagement, Motivational interviewing, Adult Learning Theory, and Teach- 
Back method (see Figure 1). For each approach, specific patient teaching skills are included that can serve as foci for targeted skill development. The description of each evidencebased approach and specific skill is discussed in relation to discharge teaching with the recognition that they apply to the broad range of teaching encounters within the scope of nursing practice.

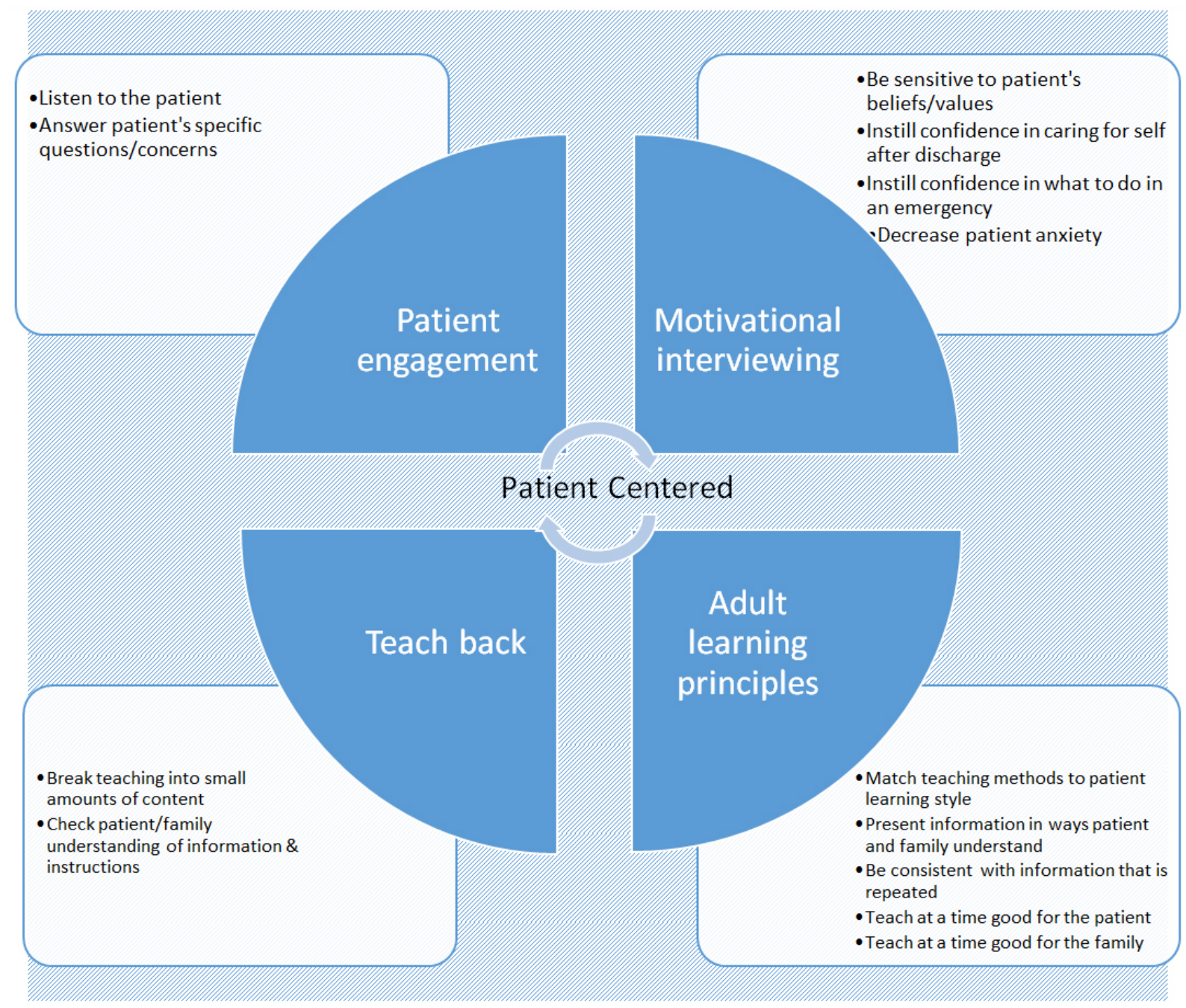

Figure 1. Theoretical framework to guide patient/family teaching

\subsection{Patient-centered care}

The need for transforming health care to a patient-centered focus is highlighted in the landmark report released by the Institute of Medicine in 2001. Patient-centered is defined as "providing care that is respectful of and responsive to individual patient preferences, needs, and values, and ensuring that patient values guide all clinical decisions." ${ }^{[25]}$ Patientcentered care has been shown to reduce medical errors and the overall cost of health care. ${ }^{[26]}$ The four evidence-based approaches to patient teaching - Patient engagement, Motivational interviewing, Adult Learning Theory, Teach-Back method - each make distinct contributions to making the patient and their goals, preferences, needs, and uniqueness central to the teaching/learning experience.

\subsection{Patient engagement}

The Agency for Healthcare Research and Quality ${ }^{[27]}$ defines patient/family engagement as "... inclusion of patients and family as active members of the health care team." Most authors agree that engagement involves consideration of the patient/family individual characteristics, perspectives and needs, including values and beliefs. ${ }^{[27,28]}$

Drenkard et al. ${ }^{[3]}$ propose a similar, but slightly different approach to patient (person) engagement. Their model consists of the following components:

- Assessing capacity for engagement, which includes consideration of health literacy, physical condition, availability of support;

ISSN 1925-4040 E-ISSN 1925-4059 
- Exchanging information and provide choices, which goes beyond just providing facts and includes alternative options for shared decision making;

- Care planning, including mutual goal setting;

- Determining appropriate interventions matched to the person's ability for self-management; and regularly evaluating to determine if the plan remains relevant and appropriate.

When persons and families are more engaged, the plan of care is more likely to be carried out since it was mutually determined. Active membership of the patient in the care team is critical and extends to shared decision making with patients and family members so that all parties are given adequate information and time to make informed decisions. ${ }^{[3,27,28]}$

Five person-centered proactive approaches by health care professionals' promote patient engagement: (1) inform me: patients know what the plan of care is, what treatments and medications are prescribed; (2) engage me: self-care instructions, reminders for medications, follow-up appointments made before discharge; (3) empower me: appropriate health literature written at a level or language the patient/family can understand, effective communication between multiple health care providers; (4) partner with me: providing patients and families with information about disease self-management, including shared decision making; and (5) support my eCommunity: shared care plans, integrated electronic care records. ${ }^{[29]}$

Specifically related to discharge teaching as an exemplar of patient teaching, guidelines for an IDEAL discharge from $\mathrm{AHRQ}^{[8]}$ prescribe: Include the patient and family as full partners; Discuss with the patient and family five key areas to prevent problems at home; Educate the patient and family throughout the hospital stay; Assess how well doctors and nurses explain the diagnosis, condition, and next steps in their care and use teach back; Listen to and honor the patient and family's goals, preferences, observations, and concerns.

These principles of patient engagement are applicable to many provider-patient encounters and to many teachinglearning situations. Patients actively involved in their health and health care are more likely to have better outcomes. ${ }^{[30,31]}$ For example, when teaching about chronic disease management, engaging patients in their learning activates them with the knowledge, skills and confidence needed to manage their long-term illnesses effectively. ${ }^{[32]}$ Engaging patients in their care has demonstrable benefits in reducing adverse events in hospitalized patients, ${ }^{[33]}$ improving patient satisfaction, ${ }^{[34]}$ and raising self-management adherence. ${ }^{[35]}$

Two specific skills need to be learned for effective patient teaching and evaluated as process measures of the quality of

Published by Sciedu Press patient teaching:

- Listen to your patient's concerns: Listening is an act of being open to understanding the patient's goals, preferences, and concerns. Being fully present in the moment of teaching is important to the active listening that is necessary in customizing the content and teaching method for each individual patient. Whole body listening (using eyes, ears, mouth, brain, heart, body) is a helpful method to actively listen and to let the patient and their family know that the nurse teacher is fully engaged in the teaching/learning process. ${ }^{[36]}$

- Answer your patient's specific concerns and questions: Engaging in dialogue with the patient and family leads to shared decision-making in addressing health care needs. ${ }^{[37]}$ Two principles are important: (1) start teaching at the patient's current level of understanding about their health condition and next steps in the plan of care; (2) assess the patient's immediate questions and concerns first.

\subsection{Adult learning theory}

Nurses practice in a wide variety of settings that all have one thing in common: the need to be able to effectively teach patients about their health. This is especially important during hospital discharge, a time of great transition and increased stress as patients and their families get ready to manage the what, when, and how-to of their health at home. Andragogy, a theory of how adults learn provides insight into how to best work with patients to facilitate their learning. ${ }^{[38-40]}$ A set of assumptions provides a guide to planning patient teaching with adult patients and family members:

(1) Self-concept: Adults value autonomy and therefore prefer choice in decisions about their learning. They are self-directed learners.

(2) Experience: Adults carry a wealth of diverse life experiences that they use to inform new learning. These experiences differ greatly from person to person and can influence everything from readiness to learn, motivation to learn, and learning style, to how and what is mentally processed and if it will be retained for future use.

(3) Readiness to learn: Adults learn best when the topic is relevant, important, and timely to their life. They are pragmatic, need-to-know learners who selectively engage in learning if they feel it is important to them, and if the learning meets their immediate goals and needs within their personal and social roles.

(4) Orientation to learning: Adults learn in order to solve a problem or improve a situation. They seek knowledge that has immediate potential for application. 
(5) Motivation: Adults are most influenced and motivated to learn by internal goals and personal expectations, rather than goals imposed or recommended by others.

Patient teaching must be understood as a process that involves taking the time to understand patient perspectives, concerns, health goals and anything that may facilitate or hinder the ability to get to those goals. ${ }^{[41]}$ Patient teaching is a process that at each step requires assessment to individualize the teaching style to the patient's preferred learning style, planning the content to personally relevant concerns, and reciprocal exchange of information with both formative and summative evaluation of learning.

Five specific skills associated with adult learning principles facilitate effective discharge teaching.

- Match teaching methods to patient learning style: Matching the teaching to the patient's preferred style of learning ${ }^{[42]}$ using the appropriate health literacy level improves the ability to retain new knowledge. ${ }^{[43]}$

- Present information in a way that patients and families can understand: Teaching using language and examples that are relevant and recognizable to the patient increases the patient's ability to be engaged in the learning and to participate in problem solving potential issues related to the discharge and beyond. The nurse needs to assess the impact of culture, language and overall health literacy on learning readiness ${ }^{[1,44]}$ and incorporate the patient's individuality in these areas into the teaching encounter.

- Be consistent with information that is repeated: Repetition of information from multiple sources is a recommended strategy for assuring retention of learning. ${ }^{[45]}$ Inconsistent information from different providers and differences in language used to communicate the same concept can be confusing to patients.

- Teach at a time that is good for the patient: Setting a time for the teaching-learning interaction when the patient can fully participate sets the stage for engagement in the learning process. Timing of the teaching should be determined based on assessment of patient readiness to learn including identification for factors that impede learning. These include physical (such as pain), cognitive (such as anxiety, cognitive impairment due to pain or medications), or environmental (such as distractions, noise, or poor lighting) factors. ${ }^{[44]}$

- Teach at a time that is good for the family: Family presence is important as it provides support for the patient, additional insight into realities impacting ability to implement discharge instructions, and reinforcement of what has been taught. ${ }^{[46]}$

\subsection{Motivational interviewing}

Motivational Interviewing (MI) is an evidence-based communication strategy to promote health behavior change by collaborating with patients to discover their motivations and resolve any conflicts that may impede positive change and adherence to recommended treatments. ${ }^{[47,48]}$ Changing health behaviors and encouraging healthy lifestyles is often a focus of patient teaching. MI allows patients to explore their own values and beliefs as they think about change. MI is recognized as part of patient-centered care that can be effectively used in the hospital by multi-disciplinary health care providers. ${ }^{[49,50]}$

Four guiding principles of MI incorporate the 'RULE' mnemonic, Resist, Understand, Listen, and Empower. ${ }^{[4]}$ RULE is a helpful reminder to focus patient teaching conversations away from 'telling' instructions, that is, resist the urge to tell the patient what to do. Instead, use the RULE to focus toward building on the patient's own motivation, actively and attentively listening for barriers, and building self-confidence in the patient's own abilities. A patient teaching example using RULE is presented in Table 1.

Table 1. RULE principles* applied to practice

\begin{tabular}{|c|c|c|}
\hline RULE Principles & Meaning & Examples \\
\hline $\begin{array}{l}\text { Resist the righting } \\
\text { reflex }\end{array}$ & $\begin{array}{l}\text { Resist telling the patient what to do, } \\
\text { instead ask the patient what can be done }\end{array}$ & $\begin{array}{l}\text { Poor: Take all your medications as directed. } \\
\text { Better: What would help you to remember to take your medications on } \\
\text { time? }\end{array}$ \\
\hline $\begin{array}{l}\text { Understand your } \\
\text { patient's } \\
\text { motivations }\end{array}$ & $\begin{array}{l}\text { Ask the patient about motivations for } \\
\text { health behavior }\end{array}$ & $\begin{array}{l}\text { Poor: I think you should take your diuretic medication every day. } \\
\text { Better: How would you feel different if you took your diuretic medication } \\
\text { every day? }\end{array}$ \\
\hline $\begin{array}{l}\text { Listen to your } \\
\text { patient }\end{array}$ & $\begin{array}{l}\text { Actively listen by showing interest and } \\
\text { being fully attentive }\end{array}$ & $\begin{array}{l}\text { Poor: Let me tell you why you must take your pill on time. } \\
\text { Better: What can you tell me about your medications? How does taking } \\
\text { your medications make you feel? }\end{array}$ \\
\hline $\begin{array}{l}\text { Empower your } \\
\text { patient }\end{array}$ & Support your patient to change & $\begin{array}{l}\text { Poor: You can change by setting a reminder to take your pill. } \\
\text { Better: What can I do to help you take your pills on time? }\end{array}$ \\
\hline
\end{tabular}


The nurse using MI employs three strategic approaches: asking, informing, and listening. ${ }^{[47]}$ By asking questions, the nurse assesses what the patient knows and what goals they want to achieve. For example, the patient may be asked what they currently do and what they want to do in the future regarding a specific behavior. With this knowledge, the nurse is able to inform the patient about unexplored options and how the options might apply to their particular situation. With attentive listening by the nurse, the patient is given the opportunity to express their wishes and identify areas in which they may need help.

Five MI techniques - open-ended questions, reflective listening, affirmations, summarizing, and eliciting ${ }^{[51]}-$ are useful during patient teaching to 1) demonstrate the nurse's active engagement in the teaching-learning session; 2) identify key patient-stated goals and motivators that can be leveraged to promote patient engagement and adherence to care recommendations; and 3) uncover barriers that may be demotivators to achieving care goals and needed lifestyle or health self-care behaviors. Incorporating MI techniques into discharge teaching helps patients who often face a lack of motivation and other hurdles in illness and the challenges of recovery, such as avoiding, overcoming, or adjusting to the limitations and disabilities associated with chronic illnesses. ${ }^{[52,53]}$

Patients with a variety of medical and psychological diagnoses have been found to successfully change health behaviors when MI was used. ${ }^{[50]}$ Use of MI increases patient engagement and patient confidence to change. For example, the effectiveness of MI compared to standard care has been demonstrated in heart failure patients with decreased readmission rates ${ }^{[54]}$ and improved antibiotic adherence in older adults hospitalized with pneumonia. ${ }^{[5]}$

In applying MI to the discharge teaching process, four specific skills help the nurse to assure use of a motivational interviewing approach to patient teaching.

- Be sensitive to the patient's beliefs and values: Using empathetic listening skills, such as paying full attention, allowing for silences, and not jumping to solutions, opens space for patients to discuss their health beliefs and values. Being sensitive to patient's beliefs helps in understanding if they wish to change or not.

- Instill confidence in what to do after going home: Patients need time to focus on important and concerning factors related to their discharge. Using affirming comments to reinforce both the accuracy of discharge instructions and ability to successfully perform personal and medical self-care is confidence building and empowering.
- Instill confidence in what to do in an emergency: The patient's ability to recognize problems and act in emergency situations is critical to preventing adverse outcomes. Confidence in knowledge of how to handle complications and emergencies empowers patients to take appropriate action in these stressful situations.

- Reduce patient/family anxiety: MI techniques generate affirmative plans for handling problems in the post-discharge period. Patients are less anxious and more confident in approaching changes and are more engaged in treatment. ${ }^{[50]}$ When health care professionals use MI, patients feel listened to, supported, and empowered.

\subsection{Teach-back method}

Teach-back is a simple, evidence-based approach for teaching-learning interactions between provider and patient. The approach incorporates patient engagement and verification of learning through an iterative process of teaching and assessing patients' understanding of health information and instructions. ${ }^{[8,56-58]}$ The provider presents information or a skill in small chucks or sound-bites, checking for understanding and proficiency after each chunk.

Evidence from a systematic review supports the use of the teach-back method in educating people with chronic disease to maximize their disease understanding and promote knowledge, adherence, self-efficacy and self-care skills. ${ }^{[56]}$ Discharge can be a stressful time for patients and their families; ${ }^{[59]}$ the information that is provided during discharge teaching can seem overwhelming and confusing. The teachback method moves beyond return demonstration by guiding the nurse to verify understanding, to correct inaccurate information, and to reinforce knowledge and skills needed for caring for self at home after discharge. ${ }^{[60]}$ Using teach-back facilitates identification of patients at risk for poor understanding and failure to implement hospital discharge instructions at home after discharge, allowing for customization of teaching at the patient's level of literacy. ${ }^{[61]}$

Two specific skills facilitate inclusion of teach-back in all teaching episodes:

- Break teaching into small amounts of content. Teaching in small segments permits focusing on one point at a time with the opportunity to check back on the patient's understanding by having the patient teach back the information or skill. Repetition and clarification reinforce the learning.

- Check patient/family understanding of information and instructions. Checking with the patient and family can involve 'talk back' by the patient in his/her own 
words about the plan for care to demonstrate not only knowledge but the ability to conceptualize the plan within the context of the patient's unique home situation. 'Demo back' is a check on the skills needed for home self-management. ${ }^{[62]}$

\section{Discussion}

Patient teaching is an essential skill set for nursing practice that achieves its highest quality when conducted using evidence-based approaches. Nurses provide patient education in every type of setting, every day. Much of this is cen- tered on discharge teaching, a primary function for hospitalbased nurses. ${ }^{[14]}$ Ineffective discharge teaching can result in a lack of patient understanding and adherence that may prolong the recovery period and, worse, result in hospital readmission. The U. S. Bureau of Labor Statistics (2018), reports that a combined $79 \%$ of nurses work in hospitals or ambulatory care. ${ }^{[63]}$ These nurses, in particular, must be able to provide effective discharge instruction, often with minimal advance notice and within compressed time periods. This is challenging, even for the most seasoned nurses. Given that $76 \%$ of new nurses seek their first job in a hospital setting, ${ }^{[64]}$ nursing academia must play a key role.

Table 2. QUALITY OF DISCHARGE TEACHING Evaluation Form

\begin{tabular}{|c|c|c|c|c|c|c|c|c|c|c|}
\hline \multicolumn{11}{|c|}{$\begin{array}{l}\text { Use this form to reflect on the way you teach your patients about preparing for going home from the hospital. Many of the responses } \\
\text { are on a 10-point scale from } 0 \text { to } 10 \text {. The words above the number indicate what the } 0 \text { or the } 10 \text { means. }\end{array}$} \\
\hline \multicolumn{11}{|c|}{ Pick the number between 0 and 10 that best describes how you self-evaluate your patient teaching session. } \\
\hline \multicolumn{11}{|c|}{ For example, circling number 7 means you feel more like the description of number 10 than number 0 but not completely. } \\
\hline $\begin{array}{l}\text { 1. In your discharge teaching session, how much information did you provide to your } \\
\text { patient about: }\end{array}$ & None & & & & & & & & reat & deal \\
\hline a. taking care of self at home after discharge & 0 & 2 & 3 & 4 & 5 & 6 & 7 & 8 & 9 & 10 \\
\hline b. emotions to expect after going home & 1 & 3 & 4 & 5 & 6 & 7 & 8 & 9 & 10 & \\
\hline $\begin{array}{l}\text { c. medical needs or treatments (for example, caring for a surgical incision, respiratory } \\
\text { treatments, exercise, rehabilitation, or taking medications in the correct amounts and at } \\
\text { the correct times) after you go home? }\end{array}$ & 0 & 2 & 3 & 4 & 5 & 6 & 7 & 8 & 9 & 10 \\
\hline d. who and when to call if problems occur after going home? & 0 & 2 & 3 & 4 & 5 & 6 & 7 & 8 & 9 & 10 \\
\hline $\begin{array}{l}\text { 2. How much practice with medical treatments or medications did you provide to your } \\
\text { patient? }\end{array}$ & 0 & 2 & 3 & 4 & 5 & 6 & 7 & 8 & 9 & 10 \\
\hline $\begin{array}{l}\text { 3. How much information did you provide to family member(s) or significant others } \\
\text { about your patient's care at home after discharge? }\end{array}$ & $\begin{array}{ll}0 & 1\end{array}$ & 2 & 3 & 4 & 5 & 6 & 7 & 8 & 9 & 10 \\
\hline $\begin{array}{l}\text { 4. In thinking about the way you 'delivered' discharge teaching to your patient, how } \\
\text { much: }\end{array}$ & Not at & & & & & & & & reat & deal \\
\hline a. did you answer specific concerns and questions? & 0 & 2 & 3 & 4 & 5 & 6 & 7 & 8 & 9 & 10 \\
\hline b. did you listen to your patient’s concerns? & 0 & 2 & 3 & 4 & 5 & 6 & 7 & 8 & 9 & 10 \\
\hline c. were you sensitive to your patient's personal beliefs and values? & 0 & 2 & 3 & 4 & 5 & 6 & 7 & 8 & 9 & 10 \\
\hline d. did you use teaching methods that were best for your patient's learning style? & 0 & 2 & 3 & 4 & 5 & 6 & 7 & 8 & 9 & 10 \\
\hline e. did you break the teaching into small amounts of content? & 0 & 2 & 3 & 4 & 5 & 6 & 7 & 8 & 9 & 10 \\
\hline f. did you check to make sure your patient understood the information and instructions? & 0 & 2 & 3 & 4 & 5 & 6 & 7 & 8 & 9 & 10 \\
\hline $\begin{array}{l}\text { g. did you instill confidence in your patient's ability to care for self at home after } \\
\text { discharge? }\end{array}$ & $0 \quad 1$ & 2 & 3 & 4 & 5 & 6 & 7 & 8 & 9 & 10 \\
\hline $\begin{array}{l}\text { h. did you instill confidence in your patient that he/she would know what to do in an } \\
\text { emergency? }\end{array}$ & $0 \quad 1$ & 2 & 3 & 4 & 5 & 6 & 7 & 8 & 9 & 10 \\
\hline i. did you decrease your patient’s anxiety about going home? & 0 & 2 & 3 & 4 & 5 & 6 & 7 & 8 & 9 & 10 \\
\hline 5. In your teaching: & Not at & & & & & & & & & ways \\
\hline $\begin{array}{l}\text { a. did you present information on self-care at home in a way your patient could } \\
\text { understand? }\end{array}$ & $0 \quad 1$ & 2 & 3 & 4 & 5 & 6 & 7 & 8 & 9 & 10 \\
\hline $\begin{array}{l}\text { b. when you repeated information for reinforcement or clarification, were you } \\
\text { consistent in the information you provided to your patient? }\end{array}$ & 01 & 2 & 3 & 4 & 5 & 6 & 7 & 8 & 9 & 10 \\
\hline $\begin{array}{l}\text { 6. Did you confirm with your patient that: } \\
\text { a. the teaching session was occurring at a time that was good for your patient? }\end{array}$ & [] Yes & & & & & & & & & \\
\hline $\begin{array}{l}\text { b. the teaching session was occurring at a time that was good for family members or } \\
\text { others who should attend? }\end{array}$ & [] Yes & & & & & & & & & \\
\hline
\end{tabular}


Learning to teach patients must begin in pre-licensure education and continue with experience acquired throughout practice. High quality education for nurses about patient teaching is a requisite for impacting patient health outcomes. ${ }^{[4,5]}$ The Theoretical Framework to Guide Patient/Family Teaching brings together four evidence-based approaches to guide student learning about patient teaching. ${ }^{[27,38,47,56]}$ Foundational education on each evidence-based approach can begin with learning about the underlying theory and outcomes achieved using the approaches. Student engagement in learning to be a skilled patient teacher will be facilitated by nursing instructors who are able to apply the same four approaches when teaching students about patient teaching. In the framework, 13 specific skills were identified that are aligned with the four approaches and provide opportunities for targeted application in simulated and real patient scenarios. These skills were derived from review of literature on patient teaching; hospital discharge preparation was used as a case example of patient teaching. Students can intentionally apply, evaluate, and refine these skills in discharge teaching and other patient teaching encounters, so that they become a routine set of practice behaviors.

In our own work, we have developed a learning module titled "Patient/Family Teaching for the Hospital Discharge Transition: An Interactive Learning Module" based on the Theoretical Framework to Guide Patient/Family Teaching. The module engages students in learning about the four theoretical approaches to patient teaching and application in the specific situation of discharge teaching. We selected discharge teaching because of the need to improve the quality of discharge teaching and patient outcomes that emerged from our research. The student experience is structured to engage students in the learning process. Students develop a discharge teaching plan in conjunction with their instructor, conduct the teaching in the simulation lab with a live model patient, review the simulation video and self-rate their performance based on the completion of the 13 discharge teaching skills (The self-evaluation tool is presented in Table 2). After the first simulated teaching, students complete the online learning module on patient/family discharge teaching, and then repeat the simulation and self-evaluation, along with a self-reflection on the entire experience. The exercise also includes a group de-briefing to enhance the learning experience.

\section{Conclusion}

The Theoretical Framework to Guide Patient/Family Teaching was developed to guide nursing students in learning foundational approaches to patient teaching through skills applicable to discharge teaching as a specific example and to the broad range of patient teaching encounters. Aligned with research demonstrating the impact of the quality of teaching skills, independent of content received, on patient outcomes, focused preparation on the recommended approaches and specific teaching skills outlined in the framework will not only improve preparation of nursing students as patient teachers but will contribute to the broad national health goals of improved patient engagement in their care and improved health outcomes.

\section{CONFLicts OF INTEREST Disclosure}

The authors declare that there is no conflict of interest.

\section{REFERENCES}

[1] Bastable SB. Nurse as educator: principles of teaching and learning for nursing practice, 5th ed. Sudbury, MA: Jones \& Bartlett; 2019. $692 \mathrm{p}$.

[2] Berwick DM, Nolan TW, Whittington J. The Triple Aim: care, health, \& cost. Health Aff. 2008; 3: 759-769. PMid:18474969 https://doi.org/10.1377/hlthaff.27.3.759

[3] Drenkard K, Swartout E, Deyo P, et al. Interactive Care Model: A framework for more fully engaging people in their healthcare. J Nurs Adm. 2015; 45(10): 503-510. PMid:26425975 https: //doi.org/10.1097/NNA.0000000000000242

[4] Weiss ME, Piacentine LB, Lokken L, et al. Perceived readiness for hospital discharge in adult medical-surgical patients. Clin Nurse Spec. 2007; 21(1): 31-42. PMid:17213738 https://doi.org/10.109 7/00002800-200701000-00008

[5] Weiss M, Johnson NL, Malin S, et al. Readiness for discharge in parents of hospitalized children. J Pediatr Nurs. 2008; 23(4): 282-295. PMid:18638672 https://doi.org/10.1016/j. pedn. 2007.10 .005

Published by Sciedu Press
[6] Weiss ME, Yakusheva O, Bobay KL. Quality and cost analysis of nurse staffing, discharge preparation, and postdischarge utilization. Health Serv Res. 2011; 46(5): 1473-1494. PMid:21517836 https://doi.org/10.1111/j.1475-6773.2011.01267.x

[7] Weiss ME, Costa L, Yakusheva O, et al. Validation of patient and nurse short forms of the Readiness for Hospital Discharge Scale and their relationship to return to the hospital. Health Serv Res. 2014; 49(1): 304-317. PMid:23855675 https ://doi .org/10.1111/14 $75-6773.12092$

[8] Agency for Healthcare Research \& Quality (AHRQ). Strategy 4: Care transitions from hospital to home: IDEAL discharge planning. [Internet]. Washington, DC: AHRQ. [cited without date]. Available from: https://www.ahrq.gov/professionals/systems/hos pital/engagingfamilies/strategy4/index.html

[9] Beebe CA, Schmitt S. Engaging patients in education for selfmanagement in an accountable care environment. Clin Diabetes. 2011; 29(3): 123-126. https://doi.org/10.2337/diaclin. 29 .3 .123 
[10] Marcus C. Strategies for improving the quality of verbal patient and family education: a review of the literature and creation of the EDUCATE model. Health Psych \& Behav Med. 2014; 2(1): 482495. PMid:25750796 https://doi.org/10.1080/21642850.2 014.900450

[11] National Quality Forum (NQF). Preferred practices and performance measures for measuring and reporting care coordination: A consensus report. [Internet] Washington, DC: NQF [cited 2010 October]. Available from: http://www .qualityforum.org/Publications/2010/1 0/Preferred_Practices_and_Performance_Measures_for _Measuring_and_Reporting_Care_Coordination.aspx

[12] Bennett JA. A case for theory triangulation. Nurs Sci Quart. 1997; 10(2): 97-102. PMid:9197723 https ://doi .org/10.1177/0894 31849701000210

[13] American Heart Association (AHA). Get with the guidelines: Target-HF patient education [Internet]. Dallas, TX:AHA. [Cited without date]. Available from: http://www . heart.org/HEARTORG/Professional/GetW ithTheGuidelines/GetWithTheGuidelines-HF/Target-H F-Patient-Education_UCM_432449_Article.jsp\#

[14] Weiss ME, Bobay KL, Bahr S, et al. A model for hospital discharge preparation: from case management to care transition. J Nurs Adm. 2015; 45(12): 606-614. PMid:26502068 https ://doi .org/10.1 $097 /$ NNA. 0000000000000273

[15] Foust JB. Discharge planning as part of daily nursing practice? Appl Nurs Res. 2007; 20(2): 72-77. PMid:17481470 https ://doi .org/ 10.1016/j . apnr.2006.01.005

[16] Reddick B, Holland C. Reinforcing discharge education and planning. Nurs Manag. 2015; 46(5): 10-4. PMid:25899225 https: //doi.org/10.1097/01. NUMA.0000463887.70222.50

[17] Bull M. Roberts J. Components of a proper hospital discharge for elders. J Adv Nurs. 2001; 35: 571-81. https://doi.org/10.104 6/j.1365-2648.2001.01873.x

[18] Horwitz LI, Moriarty JP, Chen C, et al. Quality of discharge practices and patient understanding at an academic medical center. JAMA Intern Med. 2013; 173(18): 1715-1722.

[19] Albert NM, Cohen B, Liu X, et al. Hospital nurses' comfort in and frequency of delivering heart failure self-care education. Eur J Cardiovasc Nurs. 2015; 14(5): 431-440. PMid:24934252 https : //doi.org/10.1177/1474515114540756

[20] Bergh AL, Karlsson J, Persson E, et al. Registered nurses' perceptions of conditions for patient education - focusing on organisational, environmental and professional cooperation aspects. J Nurs Manag. 2012; 20: 758-770. PMid:22967294 https://doi.org/10.1111/ j.1365-2834.2012.01460.x

[21] National Priorities Partnership. National priorities partnership and the national quality strategy. [Internet] Washington, DC: National Quality Forum. [cited 2011 September]. Available from: http://www . qualityforum.org/Setting_Priorities/NPP/ Input_into_the_National_Quality_Strategy . aspx

[22] Duncan I, Birkmeyer C, Coughlin S, et al. Assessing the value of diabetes education. Diabetes Educ. 2009; 35: 752-760. PMid:19783766 https://doi.org/10.1177/0145721709343609

[23] Funnell MM, Brown TL, Childs BP, et al. National standards for diabetes self-management education. Diabetes Care. 2011; 34(Suppl 1): S89-96.

[24] Hume K, Tomsik E. Enhancing patient education and medication reconciliation strategies to reduce readmission rates. Hospital Pharmacy 2014; 49(2): 112-114. PMid:24623862 https ://doi .org/10.1 $310 / \mathrm{hpj} 4902-112$
[25] Institute of Medicine. Crossing the quality chasm: A new health system for the 21st century. [Internet]. National Academies of Science. [cited 2011 March]. Available from: https://www .nationalacademies.org/hmd/ /media/File s/Report\%20Files/2001/Crossing-the-Quality-Chasm/Q uality $\% 20$ Chasm $\% 202001 \% 20 \% 20$ report $\% 2$ brief .pdf

[26] Shaller D. Patient-centered care: What does it take? New York, NY: Commonwealth Fund. 2007. 26 p.

[27] Agency for Healthcare Research \& Quality (AHRQ). Guide to patient and family engagement in hospital quality and safety. Available from: https://www.ahrq.gov/professionals/systems/hos pital/engagingfamilies/index.html

[28] Pelletier LR, Stichler JF. Action brief: Patient engagement and activation: a health reform imperative and improvement opportunity for nursing. Nurs Outlook. 2013; 61: 51-54. https ://doi .org/10.1 016/j.outlook.2012.11.003

[29] Perna G. 5 steps to patient engagement: A NeHC framework is created. [Internet]. Chicago, IL: Healthcare Information and Management Systems Society, National e-Health Collaborative. [cited 2012 Nov 9]. Available from: https://www.healthcare-informatics.com/article/5-s teps-patient-engagement-nehc-framework-created

[30] James J. Health policy brief: Patient engagement. Health Aff. 2013. [cited 2013 February 14]. Available from: https://www.rwjf .org/content/dam/farm/reports/ issue_briefs/2013/rwjf 404446

[31] Hibbard JH, Greene J. What the evidence shows about patient activation: Better health outcomes and care experiences, fewer data on costs. Health Aff. 2013; 32(2): 207-214. PMid:23381511 https://doi.org/10.1377/hlthaff .2012.1061

[32] Hibbard JH, Stockard J, Mahoney ER, et al. Development of the Patient Activation Measure (PAM): Conceptualizing and measuring activation in patients and patients and consumers. Health Serv Res. 2004; 39(4, Part 1): 1005-1026.

[33] Weingart SN, Zhu J, Chiappetta L, et al. Hospitalized patients' participation and its impact on quality of care and patient safety. Int J Qual Health Care. 2011; 23(3): 269-277. PMid:21307118 https://doi.org/10.1093/intqhe/mzr002

[34] Dwamena F, Holmes-Rovner M, Gaulden CM, et al. Interventions for providers to promote a patient-centred approach in clinical consultations. Cochrane Database Syst Rev. 2012; 12: CD003267.

[35] Kuntz JL, Safford MM, Singh JA, et al. Patient-centered interventions to improve medication management and adherence: A qualitative review of research findings. Patient Educ Couns. 2014; 97: 310326. PMid:25264309 https://doi.org/10.1016/j.pec. 2014 .08 .021

[36] Connolly M. Listening skills 1: how to improve your listening skills. Nursing Times. 2016; 45/46: 10-12.

[37] Armstrong MJ, Shulman LM, Vandigo J, et al. Patient engagement and shared decision-making: What do they look like in neurology practice? Neurol Clin Pract. 2016; 6(2): 190-197. PMid:27104070 https://doi.org/10.1212/CPJ.0000000000000240

[38] Knowles M. Andragogy in action. San Francisco: Jossey-Bass; 1984. $444 \mathrm{p}$.

[39] Muneja MS. A theoretical basis for adult learning facilitation: Review of selected articles. J Educ Pract. 2015; 6(31): 54-61.

[40] Ozuah PO. First, there was pedagogy and then came andragogy. Einstein J Biol Med. 2013; 21(2): 83-87. https://doi .org/10. 238 61/EJBM20052190

[41] Schector SR, Lynch J. Health learning and adult education: In search of a theory of practice. Adult Educ Quart. 2011; 6(3): 207-224. 
[42] Inott T, Kennedy BB. Assessing learning styles: practical tips for patient education. Nurs Clin North Am. 2011; 46(3): 313-320. PMid:21791266 https://doi.org/10.1016/j. cnur. 2011.05 .006

[43] Giuse NB, Koonce TY, Storrow AB, et al. Using health literacy and learning style preferences to optimize the delivery of health information. J Health Commun. 2012; 17(Suppl 3): 122-140.

[44] Beagley L. Educating patients: Understanding barriers, learning styles, and teaching techniques. J Perianesth Nurs. 2011; 26: 331337. PMid:21939886 https://doi .org/10.1016/j.jopan. 20 11.06 .002

[45] Vreeland DG, Rea RE, Montgomery LL. A review of the literature on heart failure and discharge education. Crit Care Nurs Quart. 2011; 34(3): 235-45. PMid:21670623 https ://doi .org/10.1097/CNQ. Ob013e31821ffe $5 \mathrm{~d}$

[46] Wolff JL. Roter DL. Family presence in routine medical visits: a meta-analytical review. Soc Sci Med. 2011; 72(6): 823-831. PMid:21353358 https://doi.org/10.1016/j.socscimed. 20 11.01 .015

[47] Rollnick S, Miller WR, Butler CC. Motivational interviewing in healthcare: Helping patients change behavior. Guilford Press; New York: $2008.210 \mathrm{p}$.

[48] Miller WR, Rose GS. Toward a theory of motivational interviewing. Am Psychol. 2009; 64(6): 527-537. PMid:19739882 https: //doi.org/10.1037/a0016830

[49] Edwards EJ, Bannatyne AJ, Stark AC. Twelve tips for teaching brief motivational interviewing to medical students. Med Teach. 2017; 39: 26-31. PMid:27665669

[50] Lundahl B, Moleni T, Burke BL, et al. Motivational interviewing in medical care settings: a systematic review and meta-analysis of randomized control trials. Patient Educ Couns. 2013; 93(2): 57-168.

[51] Brobeck E, Odencrants S, Bergh H, et al. Patients' experiences of lifestyle discussions based on motivational interviewing: A qualitative study. BMC Nurs. 2014; 13(1): 1.

[52] Creber RM, Patey M, Lee CS, et al. Motivational interviewing to improve self-care for patients with chronic heart failure: MITI-HF randomized control trial. Patient Education \& Counseling. 2016; 99(2): 256-264. PMid:26358533 https://doi .org/10.1016/j. pec. 2015.08.031

[53] Falahee ML, Benkert R, George NM, et al. Motivational interviewing to increase physical activity in underserved women. J Nurse Pract. 2016; 12(10): 704-709. https://doi.org/10.1016/j.nurpra .2016 .11 .002

[54] Riegel B, Creber RM, Hill J, et al. Effectiveness of motivational interviewing in decreasing hospital readmission in adults with heart failure and multimorbidity. Clin Nurs Res. 2016; 25(4): 362-377. PMid:26743119 https://doi.org/10.1177/10547738156232 52

[55] Eyler R, Shvets K, Blakely ML. Motivational interviewing to increase postdischarge antibiotic adherence in older adults with pneumonia. Consult Pharm. 2016; 31(1): 38-45. PMid:26803086 https : //doi.org/10.4140/TCP.n.2016.38

[56] Ha Dinh TT, Bonner A, Clark R, et al. The effectiveness of the teachback method on adherence and self-management in health education for people with chronic disease: a systematic review. JBI Database System Rev Implement Rep. 2016; 14(1): 210-47. PMid:26878928 https://doi.org/10.11124/jbisrir-2016-2296

[57] Sudore RL, Schillinger D. Interventions to improve care for patients with limited health literacy. J Clinical Outcomes Manag. 2009; 16(1): 20-29. PMid:20046798

[58] White M, Garbez R, Carroll M, et al. "Teach-Back" associated with knowledge retention and hospital readmission in hospitalized heart failure patients? J Cardiovasc Nurs. 2013; 28(2): 137-146. PMid:22580624 https://doi.org/10.1097/JCN.0b013e3182 4987bd

[59] Jager AJ, Wynia MK. Who gets a teach-back? Patient-reported incidence of experiencing a teach-back. J Health Comm. 2012; 17(suppl.3): 294-302. https ://doi.org/10.1080/10810730.2 012.712624

[60] Kornburger C, Gibson C, Sadowski S, et al. Using "Teach-Back" to promote a safe transition from hospital to home: an evidence-based approach to improving the discharge process. J Pediatr Nurs. 2013; 28(3): 282-291. PMid:23220377 https://doi.org/10.1016/j. pedn.2012.10.007

[61] Tamura-Lis W. Teach-back for quality education and patient safety. Urol Nurs. 2013; 33(6): 267-71, 298. PMid:24592519

[62] Sawin KJ, Weiss ME, Johnson N, et al. Development of a selfmanagement theory-guided discharge intervention for parents of hospitalized children. J Nurs Scholarship. 2017; 49(2): 202-213. PMid:28253444 https ://doi.org/10.1111/jnu. 12284

[63] Bureau of Labor Statistics, U.S. Department of Labor. Occupational outlook handbook, registered nurses. [Internet]. Washington, D.C.:Bureau of Labor Statistics [2018]. Available from: https: //www.bls.gov/ooh/healthcare/registered-nurses.htm

[64] Jaspen B. Nurses jobs shift from the hospital to the community. [Internet]. Forbes.com [cited 2015 December 24]. Available from: https://www .forbes.com/sites/brucejapsen/2015/12/2 4/more-nurse-jobs-shift-from-the-hospital-to-the - community/\#31bfa102cc2f 